\title{
TERRITORIO, TURISMO Y COMPETITIVIDAD. METÁFORAS DE ÉXITO Y DESEO DE PROGRESO EN EL MEDIO MAGDALENA
}

\author{
GREGORIO HERNÁNDEZ PULGARÍN ${ }^{1}$
}

Manizales, 2010-04-30 (Rev. 2010-08-23)

\section{RESUMEN}

El presente artículo presenta un análisis crítico de la manera en que es pensado el territorio a través de metáforas y de ideologías de tipo economicista. Lo anterior se expresa por medio de los discursos de agentes públicos y de otros agentes e instituciones que ven en el territorio un ente competitivo, orientado a la búsqueda del éxito en estrategias más próximas a las emprendidas por la empresa privada que a las construidas por una tradición del sector público interesada sobre todo en el bienestar común, y no tanto en factores como la eficacia o la utilidad, vistos como fines en sí mismos. El caso de estudio aborda el turismo (histórico, ecológico, etc.) como la actividad que, con una cuestionable racionalidad, es pensada como el medio para la realización de las pretensiones de desarrollo territorial en el Medio Magdalena (Colombia). La propuesta metodológica apela al análisis de los discursos y a la etnografía del Estado, buscando identificar y cuestionar los discursos en los que el territorio es reducido a un ente competitivo que sigue planteamientos próximos a los del "darwinismo social".

\section{PALABRAS CLAVE:}

Competitividad, Medio Magdalena, turismo, desarrollo territorial, ideologías.

\section{TERRITORY, TOURISM, AND COMPETITIVENESS. METAPHORS OF SUCCESS AND PROGRESS DESIRE IN THE MAGDALENA MEDIO}

\begin{abstract}
This article presents a critical analysis of the way in which the territory is seen using metaphors and economist type ideologies. This is expressed through public agents and other agents and institutions discourses that see in the territory a competitive entity, oriented to the search of success through strategies which are closer to those used by the private business, instead of to those built through the tradition of the public sector which are mostly interested in the common welfare rather than in factors such as efficacy or usefulness which are considered ends in themselves. This case study approaches tourism (historical, ecological, etc.) as the activity which, with a questionable rationality, is thought as the means for the accomplishment of the plans for territorial development in Magdalena Medio (Colombia). The methodological proposal appeals to the analysis of the discourses and the State ethnography, searching to identify and question the discourses in which the territory is reduced to a competitive entity which follows the approaches close to "social Darwinism."
\end{abstract}

KEY WORDS: competitiveness, Magdalena Medio, tourism, territorial development, ideologies. 


\section{INTRODUCCIÓN}

Los procesos a través de los cuales se construye territorio son múltiples y diversos. Muchos de estos son estudiados y modelados desde la perspectiva del desarrollo territorial y regional (Boisier, 1999, 2000, 2003, 2004; Cuervo, 2009; Victoria, 2009). Esta perspectiva se inscribe, según Massiris (2005), en el marco de una planeación económica y social, jalonada por el sector público, pero en la que intervienen otras instituciones y agentes privados. Las consecuencias de estas iniciativas pueden concretarse en el crecimiento económico, concebido como un "proceso y una sucesión de estados que tienen que ver con la capacidad material de producción de bienes y servicios, se trata de un fenómeno objetivo" (Boisier, 2008: 35). Simultáneamente se supone un desarrollo societal, que es entendido como un "proceso y una sucesión de estados temporales que tiene que ver con el bienestar de las personas, se trata de un fenómeno intangible y subjetivo" (Boisier, 2008: 35).

Formulaciones teóricas como la de Boisier son consideradas ocasionalmente como soporte para la promoción del desarrollo regional, aunque a veces sólo para su comprensión o análisis por parte de sectores académicos que buscan participar más en la elaboración de las agendas públicas, en los diferentes niveles territoriales.

El abordaje propuesto en este documento enfatiza el análisis crítico de algunas perspectivas de desarrollo regional que emanan de ciertos discursos académicos, pero que sobre todo son sostenidas e implementadas por los administradores locales, en este caso, de municipios del Medio Magdalena, específicamente de Mariquita, Armero-Guayabal y Honda, en el departamento del Tolima, y de La Dorada en Caldas ${ }^{2}$. 


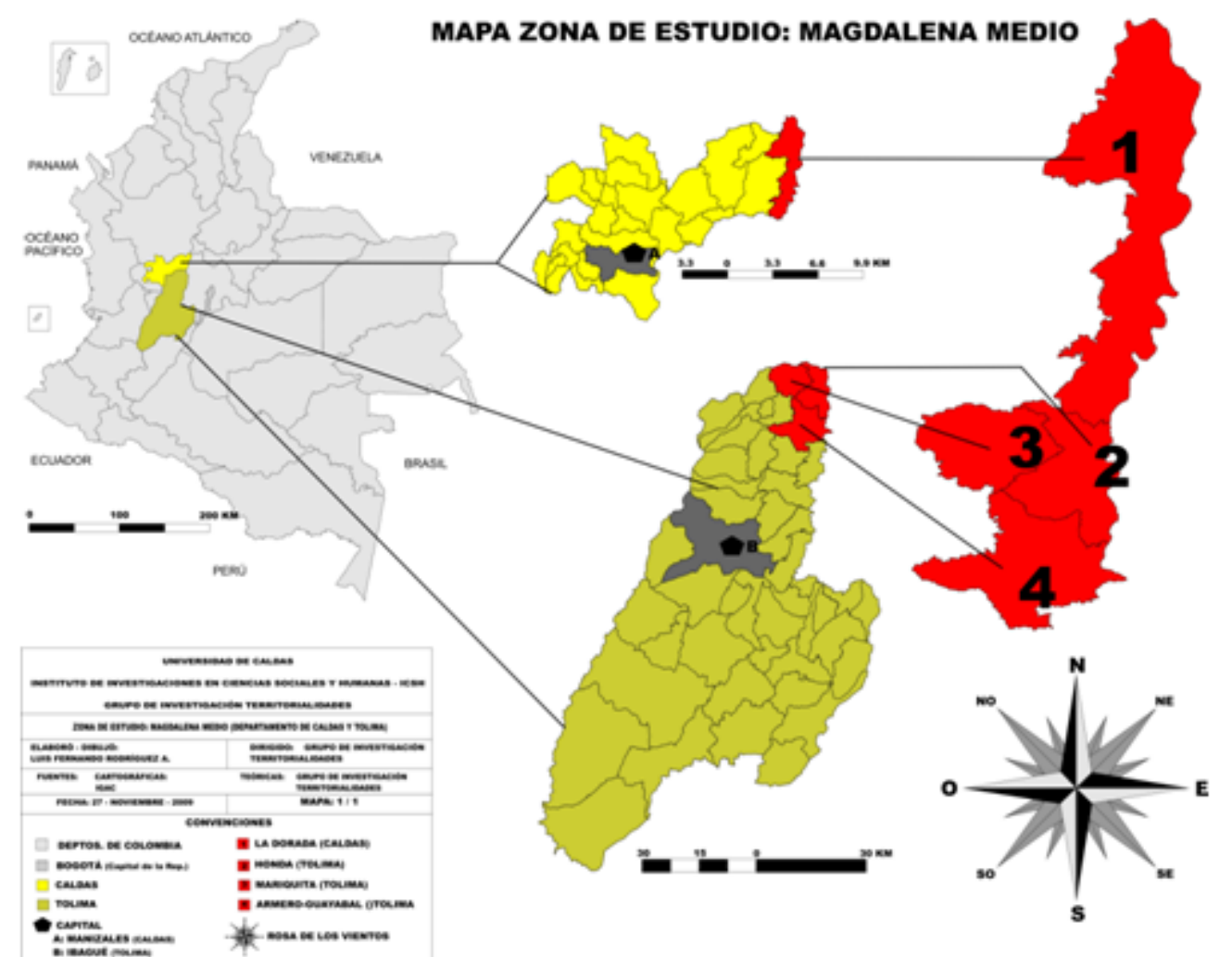

MAPA 1

La reflexión es derivada del trabajo de campo llevado a cabo en estos municipios entre los meses de abril de 2008 y enero de 2009, y de su lectura a la luz de autores que sobre todo desde la antropología, la sociología y la geografía cuestionan la manera en que se construyen modelos de desarrollo territorial en concordancia con ciertos modelos de pensamiento arraigados históricamente. Dicha reflexión preserva un tono crítico a través del cual se oculta la inevitable "conflictualidad en las disputas por modelos de desarrollo y de sociedad" (Mançano, 2008a: 2).

La aproximación efectuada fue de tipo cualitativo, centrada en la aplicación de técnicas relativas a la etnografía: entrevistas a profundidad y observación, en este caso directa. Se hizo un especial énfasis en entrevistar a funcionarios de las administraciones públicas de los municipios o de instancias privadas como las Cámaras de Comercio, influyentes en la gestión del desarrollo local. Se llevó a cabo un análisis crítico de discursos recurrentes y significativos hallados in situ, acerca de los procesos de producción y ordenación territoriales importantes, señalados por pobladores de los municipios estudiados. Esta apuesta metodológica encuentra una clara afinidad con la llamada etnografía del Estado (Trouillot, 2001), vertiente de la antropología, útil para comprender las concepciones y prácticas de los agentes estatales que intervienen en la configuración del territorio. Complementariamente, la etnografía del Estado permite reconocer el contexto y algunos de los determinantes o condicionantes (ideológicos, como se enfatiza en este caso) de las decisiones y actuaciones de instituciones estatales, las cuales se manifiestan, por ejemplo, en la concepción del territorio, en las formas de territorialidad, esto es, de control y delimitación del territorio, y en las formas de prospectar, planear e intervenir la realidad territorial. 
El ejercicio de aplicación de las técnicas y perspectivas de investigación señaladas atrás, llevó a la conclusión preliminar de que las concepciones y representaciones sobre los procesos que construyen el territorio y la territorialidad, en la mayoría de los casos, hacen parte del dominio de la economía. En otros términos, es recurrente que los actores determinantes de los municipios tiendan a reducir la complejidad territorial a las posibilidades de explotación económica vinculadas a éste. Los resultados de estas formas de explotación del territorio se articulan con las ideas de desarrollo territorial, es decir, en términos de los propios entrevistados, en "alcanzar mejores condiciones generales para la población, basados en la competitividad municipal". Dicha competitividad, condición que es pensada como indispensable para el desarrollo territorial, tiende a asociarse con actividades económicas como el comercio y el turismo, principalmente.

Es sobre todo a través del turismo que las autoridades de algunos de estos municipios tienden a pensar el territorio y el desarrollo. Otros procesos importantes en la construcción de este territorio, como serían el conflicto, las configuraciones políticas clientelares o el papel de las organizaciones sociales en el desarrollo, tienden a ser infravaloradas frente al turismo, actividad que constituye, según los propios entrevistados, una de las más importantes tablas de salvación frente a problemas de desindustrialización de municipios como Honda (Tolima) o a la falta de concreción de otras iniciativas económicas.

El análisis que sigue a continuación estudia la manera en que el turismo en municipios como Honda y Mariquita, principalmente, y en menor medida en La Dorada, es fundamental para condicionar la concepción del territorio y las posibilidades de construcción de una unidad territorial que sea más amplia que el municipio.

\section{ESCENARIOS DEL TURISMO Y LA ACTIVIDAD ECONÓMICA}

Las transformaciones en la economía mundial, orientadas a la localización de la industria en territorios con un mercado competitivo de la mano de obra, han producido importantes reconversiones mundiales. Una de las más significativas se enfoca en la búsqueda de nuevas vocaciones económicas para los territorios. En este nuevo escenario, el turismo suscita un marcado interés de muchos de los agentes e instituciones, que definen la planeación y el desarrollo territorial.

El turismo es en la actualidad la actividad económica ligada al territorio más rentable y con mayor crecimiento del planeta ${ }^{3}$. Ha incrementado en porcentajes exorbitantes los ingresos, principalmente de los países desarrollados, aunque también ha aportado en la obtención de recursos para países del Tercer Mundo ${ }^{4}$. El tipo de turismo más rentable es el internacional, que permite la inyección de dineros extranjeros a las economías locales y, en general, es concebido como un generador de desarrollo, riqueza y empleo.

Colombia ha estado relativamente marginada del turismo internacional. Hasta 2002, la imagen negativa del país en el extranjero jugaba en contra de los intereses de los oferentes de alguna de las actividades turísticas. Con el Gobierno de Álvaro Uribe Vélez, esta actividad económica ha experimentado un incremento en su potencia. Las razones son varias, aunque para efectos de este artículo se mencionarán dos. La primera, que es consecuente con la estrategia general del Gobierno para administrar la res pública, se centra en la seguridad y en los efectos cosméticos que ésta tiene sobre la manera en que se escenifica la 
realidad nacional. La segunda es la disposición de una serie de entidades y normativas que promueven la actividad entre los diferentes municipios, así como el desarrollo del sector turístico con la participación del Estado, de las comunidades y, sobre todo, de los inversionistas nacionales y extranjeros.

El conjunto de muchas de las acciones internas mencionadas y de las condiciones externas favorables, ha hecho incrementar la participación del turismo en la economía colombiana. De esta manera, "la actividad turística representó en promedio un 2,3\% del PIB entre 1999 y el 2004" (Departamento Nacional de Planeación - DNP, 2007), mientras que las metas más destacadas trazadas por el documento el Plan Sectorial de Turismo 2005-2008, elaborado por el Viceministerio de Turismo, planteaban una tasa de crecimiento gradual del PIB hasta llegar al 4,5\% en 2008, al 5\% a partir del 2010 y al $6 \%$ por año a partir del 2014 (Ministerio de Comercio, Industria y Turismo, 2008).

El crecimiento económico nada despreciable y el énfasis en la apuesta de agentes públicos de fomento de la actividad y algunos empresarios del sector, ha sido el detonante del crecimiento irracional de las pretensiones de los administradores municipales por convertir su propia localidad en un destino turístico ${ }^{5}$. Dicha conversión es concebida como el medio idóneo para la consecución del milagro económico que implica salir de una situación precaria experimentada gracias a factores como: a) la reconversión global de la industria, que ha implicado el traslado de multinacionales y la operación de transnacionales en países donde la mano de obra es, como lo dicen los empresarios, "competitiva"; b) la intención de los últimos gobiernos de reducir el Sistema General de Participación de recursos públicos dirigido a entidades territoriales (municipios, departamentos), con el presunto interés de hacer más pequeño el Estado y, claro, "competitivo", según los cánones de las aseguradoras de riesgo y de la banca internacional; y c) la baja de la producción agrícola como consecuencia del uso en la ganadería extensiva de predios rurales aptos para agricultura.

A pesar de las anteriores consideraciones, la intención analítica de este informe se orienta hacia el develamiento de algunas razones de orden simbólico que inciden en la difusión de la creencia según la cual el turismo es una excelente opción económica, al margen de las condiciones objetivas. Esto implica concebir el capitalismo como una compleja construcción cultural, que anima las iniciativas para convertir a municipios del Medio Magdalena en destinos o proveedores de productos que conformen lucrativos destinos turísticos.

Los municipios del Medio Magdalena presentan condiciones comunes a centenares de municipios que pretenden consolidar su oferta turística en el mercado del turismo interno en Colombia: clima cálido, presencia de copiosas fuentes hídricas, algunos recursos naturales y patrimonio histórico (sobre todo en Honda, una ciudad colonial que conserva un importante centro histórico). Además de eso, Mariquita, La Dorada, Honda y Armero-Guayabal cuentan con una posición geográfica favorable en términos de conexión con algunas ciudades importantes. Sin embargo, no son la localización geográfica ni el patrimonio, variables necesariamente determinantes en la conversión de un municipio en un destino turístico exitoso. De hecho hay otros factores de suma importancia. En Colombia "diversos análisis del sector turístico realizados por autoridades del orden nacional permiten detectar carencias y deficiencias en el diseño del producto, en la infraestructura y en la prestación del servicio" (Vidal, 2005: 9). En el ámbito local suelen destacarse deficiencias: 
[...] la falta de políticas de ordenamiento urbano, el impacto de la población flotante sobre la local, la insuficiencia de servicios públicos, la contaminación visual y sonora, la inseguridad, la mala utilización del espacio público y la saturación vial, originaron un impacto negativo que indudablemente afecta la calidad del turismo del Municipio [que ha existido desde los años 1950]. (Vidal, 2005: 15).

En el caso concreto del territorio del Medio Magdalena, hay otro factor que es influyente en el poco desarrollo de la actividad turística. Los municipios de interés han sufrido serias expresiones del conflicto armado después del periodo llamado "violencia política" (de los años 1940 y 1950). Más recientemente también han experimentado el conflicto derivado de la presencia y lucha por el control territorial de grupos guerrilleros y sobre todo de grupos paramilitares, que tuvieron su origen cerca de allí y que extendían hasta estos municipios su área de influencia, en connivencia con narcotraficantes y, en algunos casos, con miembros de la fuerza pública y de los administradores públicos.

Otro factor de vital importancia es el problema de crear una tradición turística y de servicio en municipios que han contado con vocaciones económicas tan disímiles en sus territorios. Sumado a esto hay problemas de administración del territorio y de reconversión, que se expresan en la economía de estos municipios.

Así, por ejemplo, San Sebastián de Mariquita presenta un importante crecimiento comercial, consecuencia de la posición que asumió como centro de abastecimiento subregional del norte del departamento del Tolima, luego de que Armero, la ciudad que gozaba dicha condición, fuera arrasada en 1985 por una avalancha de lodo causada por la erupción del Volcán Nevado del Ruiz. Su localización estratégica ha jugado un papel importante en esa reconversión económica al norte del Tolima y factores como su clima, su biodiversidad, el patrimonio histórico y el hecho de que muchos foráneos (principalmente de Bogotá y de Ibagué) llegarán recientemente a comprar y disponer locaciones de hospedaje y de servicios turísticos, han promovido la actividad turística sin ser ésta del todo organizada, ni el factor de desarrollo que pretenden los administradores locales.

Su vecina Honda, después del auge económico en diferentes periodos de su historia, experimenta hace más de 20 años un imparable declive económico que las autoridades municipales esperan superar, en gran medida a través del turismo. El declive económico se ha expresado en eventos como el cierre de la planta de la cervecería Bavaria en 2001, el cierre de dos entidades bancarias en los últimos diez años y la clausura de otras empresas manufactureras. En la actualidad, la mayoría de registros en Industria y Comercio corresponden a "hoteles, restaurantes y bares". La ganadería sigue siendo un renglón importante de la economía del municipio, aunque genera poco empleo. Para $2006^{6}$ había un promedio del $20 \%$ de registros en otras actividades comerciales. La pesca sigue siendo un renglón importante para la economía de las mayorías pobres del municipio y la llamada "subienda", el periodo de desove de peces en el río Magdalena entre enero y abril de cada año, se convierte en un fenómeno que atrae turistas. A pesar de la disposición para el turismo en este municipio, provisto de un significativo patrimonio arquitectónico y de una considerable infraestructura, esta actividad no presenta el dinamismo esperado.

En La Dorada las expectativas han girado menos sobre el turismo que sobre su vocación comercial y pecuaria. Su localización la ha convertido en un centro de comercio en el eje del sur del Medio Magdalena. Los pocos inventarios que se han hecho sobre turismo son superficiales y reconocen la existencia de 
potencialidades como el constante número de visitantes que llegan al municipio, al igual que falencias como el desorden de la actividad, la precaria infraestructura hotelera y la mala imagen proyectada no sólo por la falta de una "identidad turística"7, sino también por el asocio del municipio con el conflicto.

Armero-Guayabal es el municipio que presenta la actividad económica más precaria de los cuatro estudiados. Allí ni el comercio, ni la industria, ni siquiera el turismo se vislumbran como fuentes de ingreso a corto plazo que sustenten el desarrollo del municipio.

A pesar de los antecedentes y perspectivas dispares con relación a la participación del turismo en la economía, este renglón presenta una participación poco significativa en el departamento. El sector empleado en la metodología de medición económica del Departamento Nacional de Estadística (DANE): Servicios de hotelería y restaurante, representaba en el departamento del Tolima para el año 2000 el 3,44\% del PIB; en el 2004 la cifra era del 3,05\%, mientras que para el año 2007 mostraba una participación no muy diferente: 3,20\% (DANE, 2010). Aunque las cifras no están discriminadas municipalmente, Honda y Mariquita se suponen con una participación muy austera frente a otros destinos más posicionados en el departamento del Tolima.

Según el impreciso instrumento de medición del DANE, en el caso de Caldas la participación del turismo en las cuentas departamentales es menor, aunque presenta un comportamiento de reducción similar a lo ocurrido con el departamento del Tolima. Para el año 2000, por ejemplo, el rubro "Servicios de hotelería y restaurante" constituía el 2,27\% del PIB departamental, presentando una reducción hasta representar el 2,19\% en 2004 y un 1,92\% en 2007 (DANE, 2010). A pesar de lo que puedan sugerir estas cifras, es necesario destacar nuevamente que La Dorada no ha presentado históricamente una vocación turística a diferencia de otros municipios de Caldas.

\section{ÁMBITOS CONCEPTUALES}

Cuando se habla del turismo en este contexto de análisis de procesos de producción del territorio, se busca la relación que existe entre éste y diferentes ámbitos de problematización teórico-conceptual. El primero de ellos es relativo al ámbito del poder y del discurso, específicamente cuando a través de esta inextricable díada se crean y recrean visiones del mundo que son difundidas y asumidas como naturales. Bourdieu y Waquant (2000) elaboran un análisis que sirve de soporte teórico para lo que aquí se quiere expresar. Estos autores muestran la manera en que los productores de un lenguaje políticamente correcto y técnicamente funcional han naturalizado una visión de mundo orientada por valores propios del capitalismo moderno, la cual se reproduce en muchos ámbitos de acción, como consecuencia de las relaciones asimétricas entre los productores y quienes asumen de esas formas del lenguaje para referir, oficialmente, el mundo en el contexto pragmático e interesado de la globalización.

Una vertiente de los estudios culturales que ha tomado mucho auge en los Estados Unidos y en América Latina, la de estudios de la modernidad/colonialidad (Escobar, 2005; Mignolo, 2008; Castro Gómez, 1998), resulta útil para entender también la manera como en el contexto actual de la globalización existe una colonización discursiva de los países del primer mundo, sobre los países periféricos. Así las cosas, nociones como las de éxito, 
competitividad y, en su conjunto, aquellas ideas que soportan el management o la economía aplicada, han sido creadas en Estados Unidos o Europea y corresponden a una lógica diferente a la de poblaciones del tercer mundo como la latinoamericana.

La expresión de la relación discurso/poder en este análisis se objetiva, principalmente, en la manera en que el territorio es pensado a través de esas categorías que reproducen valores como la competitividad, la competencia, la estrategia y otra serie de expresiones de talante eminentemente empresarial que constituyen, en cierta medida, hojas de ruta para las políticas y las acciones a través de las cuales se concibe y se tiene injerencia sobre el territorio y sobre lo público. Ese reduccionismo sirve para pensar a los sujetos sociales, las relaciones sociales, la cultura, el Estado y el medio natural, como elementos de una función económica de maximización, operada constantemente a través del turismo.

Otro autor latinoamericano, Milton Santos (2004), destaca también que en el marco de la globalización los territorios se construyen en consecuencia con vectores de racionalidad dominante, en los que operan discursos y prácticas que hacen de la competitividad el marco para las relaciones asimétricas entre los diferentes territorios y las racionalidades que se conjugan en éstos.

El segundo ámbito de análisis se centra en una distorsión de la realidad. Esa distorsión procede de la concepción mercantilizada del territorio y se hace evidente cuando una de las condiciones intrínsecas a la construcción de un territorio, como es el conflicto y muchas formas de violencia física, tiende a ser obviada, como una falla o un imperfecto del producto que se pretende ocultar al cliente. Esta concepción que oculta, es parte de una política nacional en la que se crea, dicho en términos de Baudrillard (1988), un simulacro de territorio seguro, que suplanta eficazmente la conflictiva realidad. Esta construcción simulada de la realidad es mucho más eficiente cuando se ponen en juego los medios de comunicación que cuando se expresa en un "discurso explícito" (García, 1987), es decir, aquel que construye la mejor versión de la propia cultura, frente a cualquier sujeto foráneo que interroga sobre aquella.

El tercer ámbito conceptual es el de la invención de la tradición (Hobsbawn \& Ranger, 1983), como condición indispensable para la práctica del turismo. La incorporación de prácticas estereotipadas en las rutinas de los habitantes de un pueblo turístico, es una puesta en escena de los discursos economicistas que orientan la concepción del otro y del mismo hecho potencial turístico (Richman, 2008). Desde esta perspectiva, tendríamos que el turismo exige hacer de la cultura una variable dependiente de la economía o, más concretamente, del mercado turístico.

\section{TURISMO, DESARROLLO Y TERRITORIO: EL MODELO DE LA COMPETITIVIDAD}

La intención de valerse del turismo como medio para alcanzar el desarrollo, se sustenta en la utilización de un sofisticado lenguaje propio de los ámbitos del sector empresarial. Este lenguaje incorpora reiteradamente $y$, a veces sin mucho sentido, nociones como: ventajas comparativas, estrategia, éxito y, la más significativa de todas, competitividad. 
Este lenguaje es frecuentemente usado por miembros de las administraciones municipales en los municipios de análisis. Frente a la pregunta sobre cuáles eran las perspectivas económicas del municipio, los secretarios de economía y de planeación entrevistados esperaban obtener la competitividad del municipio a través del turismo, para lo que señalaban una serie de estrategias que habían implementado y esperaban realizar para obtener tal desarrollo, y en consecuencia, para constituirse en municipios exitosos.

El asunto sería solamente anecdótico si la utilización recurrente de ese lenguaje fuera una cuestión neutral, cosa que no es. De entrada esa forma de administrar los bienes públicos sugiere un cambio de la práctica política, que se enmarca claramente en la implementación de ideologías y maneras del ámbito privado. Dicho en otros términos, existe una marcada tendencia a concebir la administración municipal, ya no como una instancia política a cargo de una realidad social compleja: el municipio, sino como un equipo que tiene a su cargo una población y una serie de fenómenos para los que la concepción de la empresa tiende a ser empleada. Éste puede ser asumido como un cambio en las metáforas para la acción, que incluye ciertos preceptos: los hombres son recursos o clientes, la finalidad es la utilidad o la rentabilidad. Detrás de estos discursos, obviamente están los principios inherentes al sistema que sustenta estas concepciones y lenguajes: el capitalismo con su individualismo, tan claramente justificado por buena parte de los sistemas políticos y filosóficos influyentes desde el siglo XIX (Polanyi, 1994; Sahlins, 2004; Dumont, 1978), y tan difundidos, no sin algunas variantes más chocantes y perversas, a través del lenguaje del liberalismo propio de los tiempos actuales. En el lenguaje y concepción de los funcionarios principalmente relacionados con la planeación, la economía o el desarrollo de los municipios de análisis, vemos cómo han empezado a entrar en desuso ideas que han fundamentado varios modelos del estado: justicia social, igualdad, equidad, solidaridad, las cuales han sido remplazadas por leitmotiv, slogans o clichés, que se ponen claramente en evidencia cuando se piensa en el futuro del municipio. ${ }^{8}$

El territorio es para los secretarios de áreas económicas del los municipios un recurso, un potencial para el desarrollo económico. El término más común para referir el territorio por estos días es competitividad, incluso escuché frecuentemente la noción de territorios competitivos. Este término es muy afín a aquello que Herbert Spencer inauguró en el siglo XIX: el "darwinismo social" (Harris, 1987). Los territorios son metafóricamente transformados en organismos que viven a expensas de los demás, pero si resultan menos apetentes o lo suficientemente ineptos como para no acabar con sus vecinos en ese entorno dantesco que se llama mundo globalizado, desaparecen, para ser más precisos, mueren. Los territorios mueren metafóricamente. Se cree que lo hacen cuando no aplican las recetas apropiadas, cuando no se pliegan al turismo, por ejemplo, como tabla de salvación, eso creen además de los administradores locales, funcionarios de las agremiaciones de comerciantes y empresarios locales.

En esa perspectiva, los municipios vecinos se ven como una competencia directa. Las rivalidades tradicionales entre municipios que conforman una región o un territorio con características compartidas tienden a hacerse más agudas, al menos en el discurso. En este sentido, se entiende el resentimiento expresado en privado, ya no sólo por funcionarios, sino también por varios entrevistados de Honda hacia su vecino San Sebastián de Mariquita. Aunque habría que mencionar una razón adicional al talante competitivo asociado al turismo: el declive de Honda y el surgimiento de Mariquita como centro comercial del norte del departamento del Tolima, a pesar de que, como diría un funcionario de la Cámara de Comercio de Honda, vinculado a la promoción del turismo: su territorio presenta "más ventajas comparativas (patrimonio histórico, eventos) que 
Mariquita, el problema es que no se han convertido en ventajas competitivas (el patrimonio potenciado, es decir, asumido estratégicamente)".

En esa misma lógica se piensan los demás municipios vecinos, lo que evidencia una vez más la inoperancia de la solidaridad en esta concepción empresarial del territorio. Pero esta situación encarna una paradoja. Cuando se leen las normativas y estrategias para la competitividad territorial (como las Agendas Departamentales para la Competitividad), diseñadas por los "gestores departamentales", y en general cuando se analizan las estrategias habituales que ha tenido el desarrollo turístico en diferentes escenarios donde la alternativa turística ha calado, se nota que los destinos exitosos normalmente no se corresponden con una unidad territorial municipal, sino que incluyen productos ofrecidos por varios municipios, y claro está, por muchos empresarios que trabajan según el principio de cooperación de los llamados clusters, de las cadenas productivas o de las cadenas de valor. Pues bien, la implementación de estas iniciativas conjuntas, cuando no son jalonadas por los propios empresarios, es sumamente difícil de lograr. La asociatividad, como denominan la tendencia a establecer redes de prestación de servicios, ha sido problemática de emprender incluso en experiencias de consolidación de destinos turísticos con más trayectoria en Colombia como los departamentos de Quindío y Risaralda. Esta es una paradoja que no ha podido sortearse: se pretende realizar muy bien lo que indican los principios individualistas de la competitividad, pero ha resultado menos claro asumir esa otra estrategia, la de cooperación como un medio para la finalidad utilitaria que podría beneficiar a muchos.

Desde una perspectiva de análisis que enfatiza la globalización y sus paradojas, Milton Santos señala: "En una situación de extrema competitividad como ésta que vivimos, los lugares hacen eco de los embates entre los diversos actores, y el territorio como un todo revela los movimientos de fondo de la sociedad. La globalización, con la protuberancia de los sistemas técnicos y de la información, subvierte el antiguo juego de la evolución territorial e impone nuevas lógicas" (2004: 67). Para el caso, las lógicas de la racionalidad dominante en el lúgubre contexto de la economía de corte neoliberal que a cada momento va permeando más marcadamente los contextos donde no operaba esa misma lógica. El resultado supone una "territorialización del capital", originaria a su vez de una "desterritorialización de otros sectores sociales": campesinos (Mançano, 2008a: 337), ciudadanos de a pie o víctimas del conflicto armado, habituados a guiarse en su territorio por doctrinas menos individualistas.

Hay varias razones que sustentan el uso de la doctrina de competitividad territorial. Una de ellas es el mencionado auge del turismo global. En esa medida, resultaría incomprensible al menos no intentar participar del negocio más rentable globalmente. Segundo, existe una tendencia de organismos internacionales: BID $^{9}$, CEPAL $^{10}$, UN (UNESCO, WTO) ${ }^{11}$ o USAID, que se encargan de crear y reproducir los lenguajes y en general las estrategias de competitividad para el desarrollo territorial del tercer mundo, que implican la doctrina de la competencia y a veces el uso de un lenguaje muy técnico y de unas metáforas cuestionables ${ }^{12}$. Desde la aguda perspectiva analítica de autores como Escobar $(1999,2005)$, ésta sería una expresión más de la forma de dominación discursiva que subyace al tema del desarrollo. Por su parte, Wood y Chambers (citados en Pabion, 2008) plantean que en el caso del turismo, las ejecutorias en contextos específicos corresponden casi siempre a la implantación de modelos externos promovidos por instituciones y actores específicos, que no son cuestionados o apropiados a la luz de las realidades y reinterpretaciones locales. 
Pero más allá de esto, se destaca el papel de las normativas y de los especialistas en la difusión de los lenguajes y de las estrategias que ubican el turismo como la opción salvadora de un territorio o, en este caso, de un municipio específico. Para empezar, cabría señalar que cada municipio debe comprometerse con la elaboración de un documento en el que se planee y racionalice la actividad turística, el llamado Plan de Desarrollo Turístico. Si bien algunos de los funcionarios públicos entrevistados no conocían a profundidad este documento rector, manejan un lenguaje que expresa una marcada recurrencia de términos como estrategia y competitividad, que corresponde a una matriz o a un modelo de lenguaje que se supone suficiente para promover la eficacia (y otros valores de este tipo) en las prácticas de gestión del municipio en general y del turismo en particular.

Para el ámbito de las empresas públicas de una ciudad de Colombia, López y Hernández (2003) mostraban cómo en este sector tiende a presentarse una utilización a-crítica de modelos de gestión, constituyendo un fenómeno de replicación catalogado como moda. Este fenómeno es jalonado numerosas veces por los consultores que fungen de vendedores de éxito o de experiencias exitosas. Hay casos en los que los consultores contratados no conocen la realidad sobre la que se está proponiendo el modelo o el plan, pero sí conocen muy bien los formatos y las convenciones en la construcción de estrategias que tienden a ser similares (crear buena imagen, seguridad, asociatividad, etc.), lo que no garantiza que se deriven de su implantación unos resultados consecuentes con la realidad y las aspiraciones. Algo similar ocurre en varios municipios con el turismo.

Estos intentos por "racionalizar" la actividad turística (confiando en los discursos de organismos internacionales, del Ministerio de Comercio, Industria y Turismo o de los consultores) generan prácticas de administración públicas y expectativas irracionales entre los administradores y la población local. Esta última, se pliega a las expectativas que son despertadas por administradores y empresarios. Al respecto es necesario resaltar que las comunidades periféricas, marginales 0 vulnerables en la economía de una población, cuando ven en peligro los pocos ingresos que tienen: "estarían dispuestas a aceptar aquellas alternativas que puedan generar riqueza (por impopulares que sean)." (Llurdés et al. 1999: 125).

\section{LA OCULTACIÓN DEL MAL A LOS OJOS DEL TURISTA}

El éxito del turismo que se quiere emprender en estos municipios requiere de una imagen favorable en la que el conflicto y las expresiones de violencia de otro orden no tengan cabida. Con base en esto, las autoridades nacionales y municipales han promovido una serie de estrategias para mantener una cierta seguridad a los ojos de los foráneos. Esta estrategia tiene dos componentes: uno de control policivo y militar de las carreteras y de los principales productos turísticos, y otro de ocultación de la realidad del conflicto.

La estrategia mediática, con la que se ha construido un simulacro de la realidad nacional es emprendida generalmente por el Ministerio encargado del ramo. A través de coloridas y armoniosas imágenes que se centran en campañas publicitarias, se construye una realidad alternativa. La campaña más exitosa, para el turismo nacional, se centró en el lema "Vive Colombia viaja por ella". Esta campaña publicitaria mostraba en la televisión el resultado del componente activo de ella: disponer de condiciones de seguridad en diferentes vías nacionales para organizar caravanas turísticas a varios municipios. El éxito fue rotundo, Colombia 
desde allí dejó de ser, al menos para una gran parte de los pobladores nacionales, un lugar conflictivo o violento.

Lo que se oculta con ese simulacro es una ominosa historia de violencia. Honda y Mariquita hacen parte de la región del norte del Tolima y de los territorios de influencia del Magdalena Medio: esta subregión ha sido influenciada por el ELN, a través del frente Bolcheviques del Líbano, y más recientemente por las FARC, con el frente Tulio Varón. El Magdalena Medio, por su parte, carga un estigma en su denominación por ser un territorio de confrontación entre grupos de izquierda (no todos armados e ilegales) que se han asentado allí, y más recientemente por el sangriento y extremo control ejercido por las Autodefensas Unidas de Colombia (AUC), que tuvieron sus orígenes en Puerto Boyacá, un municipio vecino de La Dorada.

Los actos de violencia recientes que permanecen en un hermético silencio en las mismas poblaciones, por temor y por imagen, tienen que ver con el accionar paramilitar. Tres estructuras paramilitares tenían influencia en Honda y Mariquita: el bloque Tolima de las AUC, que dejó las armas en octubre de 2005; el frente Ómar Isaza, que las dejó en febrero de 2006, y el bloque Centauros, que lo hizo en septiembre de 2005. La cantidad de asesinatos, extorsiones y desapariciones que están confensando en la actualidad, no se corresponde con las cifras presentadas por las autoridades policiales. La razón es que la mayoría de asesinatos implicaban prácticas extremas de descuartizamiento o de quema de restos humanos que eran arrojados a los ríos cercanos. A pesar de la desmovilización de las principales estructuras, en la actualidad operan algunos de estos hombres que no se desmovilizaron y siguen llevando a cabo los mismos actos violentos, un poco más a sus anchas, considerando la afirmación oficial, según la cual ya no hay paramilitares en la zona, sino sólo delincuencia común o bandas criminales emergentes.

La pervivencia de estos grupos e individuos tiene que ver con que aún se conservan los intereses estratégicos que justifican su accionar: "[...] el dominio sobre el río Magdalena y de los ejes viales que conectan el centro con el norte y el sur del país, con puntos claves de vigilancia del transporte hacia el sur y el norte del departamento. El cobro de gramaje sobre la coca [proveniente] del Putumayo, Caquetá y Huila [...] así como el cobro de vacunas a los arroceros y el robo de gasolina" ${ }^{13}$.

Algunas de las consecuencias territoriales de esta práctica fueron el desplazamiento forzado y la apropiación de tierras por parte de empresarios prósperos de los municipios.

Aunque no se habla mucho del conflicto, el tema de los desplazados sí resulta un problema para los administradores municipales, al traer consecuencias estéticas que afectan la imagen municipal. De ahí que en Honda a los desplazados que lleguen se los invite a irse a otra ciudad y se les dé el pasaje para hacerlo. De ahí también, la confrontación de la administración local, de algunos habitantes de bien y hasta del Gobierno Nacional, con 357 familias desplazadas que ocuparon el Bosque de San Sebastián de Mariquita, una mancha en la conmemoración de los doscientos años de la muerte de José Celestino Mutis, celebrados en 2008, en el marco de una estrategia para recuperar el turismo, a lo largo de la llamada ruta mutis.

Estas expresiones que hacen parte de la producción de territorio tienden a ser, antes que comprendidas como parte de un conjunto de lecciones aprendidas que aporten al desarrollo, negadas y ocultadas por las administraciones públicas 
locales. El hecho de centrarse en el turismo como actividad fundamental en el desarrollo del territorio del Medio Magdalena, hace que se acuda a la creación ficticia de una tranquilidad inexistente: la negación de la presencia de paramilitares, de guerrilla, de desplazados, de delincuencia común y de la inequidad social, lo cual ha generado gran parte de la situación conflictiva del Magdalena Medio.

Gran parte de la situación conflictiva se ha concentrado en las zonas rurales de los municipios. De ahí que no resulte extraño que no haya un énfasis por vincular a pobladores rurales para los planes establecidos. La apuesta sigue siendo urbana y orientada a sitios con accesos viales fáciles, lo que constituye una muestra del abandono del campo y del efecto cosmético de la seguridad en la que se sustenta parte de la iniciativa de convertir a los municipios en destinos turísticos.

El desempleo, la pobreza, el desplazamiento y la redistribución de la tierra, a veces con el influjo de actores armados, siguen estando presentes en los territorios rurales de esta zona, donde las presiones recientes de los grupos armados de derecha han tendido a estigmatizar formas de organización social que abanderen proyectos, tendientes, por ejemplo, a la generación de nuevas estrategias que permitan la reproducción social a través de la combinación de distintas actividades económicas que les permita participar en varios mercados y reducir los niveles de precariedad, como ocurre en otros contextos donde se ha asumido el reto que trae consigo la "nueva ruralidad" (Torres, 2008; Barrera, 2006; Herrera, 2009), es decir, aquella basada en "nuevas orientaciones productivas como el cultivo de bioenergéticos, plantas medicinales, artesanías, turismo rural, forestación, agricultura orgánica, agricultura sostenible, granjas de especies menores, empresas de servicios rurales y una mayor integración de la cadena agroproductiva y comercial con expresiones organizativas en el campo, la ciudad y en el extranjero." (IICA, 2000: 8).

\section{LA INVENCIÓN DE LA TRADICIÓN}

Un problema que enfrentan las administraciones locales para hacer que los modelos de desarrollo turístico presenten buenos resultados, es la carencia de aquello que los administradores locales llaman una "cultura del servicio" y la "imagen que proyecta el municipio". Diagnósticos elaborados en Honda para su Plan de Desarrollo Municipal, por ejemplo, indican la existencia de anarquía en el uso del espacio público por parte de los pobladores urbanos, usos indebidos del patrimonio, falencias en la seguridad, incremento de vendedores informales que afectan la estética urbana y las quejas de clientes (turistas) mal atendidos. Este panorama, que hace parte de las tradiciones locales, es visto como incompatible con el desarrollo de la actividad turística y, en consecuencia, del territorio.

La negativa a pensar esos factores culturales locales como inconvenientes, se puede rastrear en textos de ligereza conceptual como el siguiente:

El desarrollo de una identidad local por la ciudadanía y de una imagen exterior son factores que pueden llegar a tener su importancia en los procesos de movilización de las capacidades endógenas de una zona determinada. Algunos sistemas locales caracterizados por determinados rasgos culturales, como por ejemplo de población inmigrante mayoritariamente originaria de una misma zona, tienen ya una fuerte identidad fraguada y plena conciencia de sus fortalezas y debilidades (Llisterri, 2001: 14. Las cursivas son mías). 
Según este enfoque, lo que se requiere es una forma de ingeniería social que logre convertir al ciudadano y al poblador en un empresario. En otros términos, es necesario emprender la difícil labor de transformar esas estructuras inveteradas en la mayoría de esquemas de conducta de los pobladores locales, en unas estructuras que orienten un pensamiento y acción centrados en valores diferentes, tales como la eficiencia y la productividad.

La inculcación de esos valores inexistentes se promueve a través de actos con los que se pretende la invención de la tradición, y este proceso "se refiere al conjunto de prácticas, regidas normalmente por reglas manifiestas o aceptadas tácitamente y de naturaleza ritual o simbólica, que buscan inculcar ciertos valores y normas de comportamiento por medio de la repetición, lo que implica de manera automática una continuidad con el pasado." (Hobsbwam \& Ranger, 1983: 3).

Es evidente que en los municipios con más tradición turística como Honda y Mariquita, se han ido desarrollando espontáneamente prácticas de "servicio al cliente", apropiadas para el negocio turístico. No obstante, las campañas emprendidas por gremios como las Cámaras de Comercio y las administraciones municipales actuales tienden a forzar un cambio en los modos de ser y en las relaciones sociales, a veces no contando con los conocimientos ni, en consecuencia, con las herramientas necesarias para llevarlo a cabo.

Los administradores y empresarios locales tienden a concebir esa posibilidad de cambio mucho menos difícil de lo que realmente es. Un hecho derivado de aquello que se viene argumentando sobre la imposición de modelos, es que en lugar de potenciar las concepciones y prácticas locales como importantes dentro del desarrollo territorial, se pretenda transformar radicalmente a los pobladores, como indicaría un modelo de planificación del territorio construido en el maravilloso mundo de la abstracción.

\section{Anotaciones finales}

La obtención de mejores condiciones de vida para los habitantes del Medio Magdalena, es una meta que deben trazarse los agentes económicos, la administración pública, la academia y la sociedad civil. Los medios para lograrlo son diversos. El turismo podría ser una de las múltiples actividades que podrían ser implementadas para lograr tal propósito. No obstante, se requiere de una visión más reflexiva y racional de las implicaciones del turismo, que parta del conocimiento de las condiciones que han estructurado el territorio.

Sea a través del turismo o de otros medios, es necesario que se haga caso omiso de preceptos propios a los del darwinismo social, en los que el otro, en este caso, el otro municipio, el otro territorio, es un competidor que es necesario abatir. En ese sentido, debe pensarse que, por el contrario, la cooperación territorial es un medio para alcanzar el desarrollo de un territorio cualquiera.

Las zonas rurales afectadas tan claramente por el conflicto y relativamente marginadas en los planes de las economías locales, requieren de una mayor atención. Debería promoverse en ellas verdaderas alternativas de desarrollo, involucrándolas en iniciativas realmente apropiadas, que potencialicen sus recursos y las integren a las cabeceras urbanas a través de un modelo armonioso no competitivo. 
En ese mismo sentido, es necesario que los actores que participen en la búsqueda del desarrollo territorial, conozcan y reconozcan muy bien sus potencialidades. En esa medida, pretender un poco ingenuamente, por ejemplo, cambiar las estructuras de pensamiento y de acción de la mayoría de sus pobladores en función del turismo, sería menos adecuado que canalizar dichas cualidades culturales e identitarias en otros proyectos económicos más afines y viables.

\section{BIBLIOGRAFÍA}

- Alburquerque, F. (2004). "El enfoque del Desarrollo Económico Local". Cuadernos DEL, Número I (OIT Argentina).

- Barrera, E. (2006). Turismo rural: nueva ruralidad y empleo rural no agrícola. Montevideo: Cinterfor/OIT.

- Baudrillard, J. (1988). "Simulacra and simulations". En: Mark Poster (ed.), Selected Writings. Stanford: Stanford University Press. pp.166-184.

- Boisier, S. (1999).Teorías y metáforas sobre desarrollo territorial. Santiago:

CEPAL.

(2000). Conversaciones sociales y desarrollo regional. Talca: Editorial de la Universidad de Talca.

- (2003). El desarrollo en su lugar. Santiago de Chile: Instituto de Geografía, Universidad Católica de Chile.

- _ (2004). "Una (re)visión heterodoxa del desarrollo (territorial): un imperativo categórico". Estudios sociales, Año/Vol. XII(023). pp. 10-35.

- (2005). "¿Hay espacio para el desarrollo local en la globalización?". Revista de la CEPAL, 86. [Santiago de Chile].

- _ (2008). "Fundamentación teórica de la planificación y del desarrollo regional". En: Desarrollo regional y planificación urbana, cuadernos de clase 1. Manizales: UAM.

- Bourdieu, P. \& Wacquant, L. (2000). "La lingua franca de la revolución neoliberal. Una nueva vulgata planetaria". En: Le Monde diplomatique, Capital Intelectual S.A., Año 1, número 11. 2000: 12-13.

- Castro Gómez, S. (1998). "Geografías poscoloniales y translocalizaciones narrativas de ?lo latinoamericano'. La crítica al colonialismo en tiempos de la globalización". En: Follari, Roberto \& Lanz, Rigoberto (comp.), Enfoques sobre Posmodernidad en América Latina. Caracas: Editorial Sentido. pp. 155-182.

- Cuervo, M. (2006). "Globalización y territorio". En: Serie Gestión Pública, 56 (julio) CEPAL-ILPES. Santiago de Chile.

- Cuervo R., J. I. (2009). "El enfoque de políticas públicas como herramienta de análisis para impulsar el desarrollo regional". En: Cuadernos de clase 01-02, Maestría Desarrollo regional y planificación del territorio. Manizales: Universidad

Autónoma. Departamento Nacional de Estadística. (2010). Cuentas nacionales departamentales. Bogotá: DANE. En Internet: http://www.dane.gov.co/index.php?option=com_content\&task=catego ry\&sectionid $=33 \& i d=59 \& \mid$ temid $=241$

Departamento Nacional de Planeación - DNP. (2007). Agenda interna para productividad y la competitividad. Documento regional Tolima. Bogotá: DNP.

- Dumont, L. (1978). Homo ÆEqualis I: genèse et épanouissement de l'idéologie économique. Paris: Gallimard.

- Escobar, A. (1999). El final del salvaje. Bogotá: ICANH-CEREC 
- Escobar, A. (2005). Más allá del tercer mundo: globalización y diferencia. Bogotá: ICANH.

- García, J.L. (1987). "El discurso del nativo sobre su propia cultura. Análisis de un Concejo Asturiano". En: Fueyes Dixebrees de Lietres Asturianes. Oviedo.

- Goded, M. (1998). El impacto del turismo sobre el desarrollo económico: el caso de argentina. Tesis doctoral. Madrid: Universidad Complutense.

- Harris, M. (1987). El desarrollo de la teoría antropológica. Madrid: Siglo $\mathrm{XXI}$.

- Herrera, R. (2009). Estudios sobre turismo rural en Chile. Santiago: IICA.

- Hobsbawm, E. \& Ranger, T. (1983). The invention of tradition. Cambridge University Press.

- Instituto Interamericano de Cooperación para la Agricultura - IICA. (2000). "El desarrollo rural sostenible en el marco de una nueva lectura de la ruralidad". En: Nueva ruralidad. Panamá: CIDER.

- López, L. \& Hernández, G. (2003). Propuestas administrativas en las empresas de servicios públicos de Manizales: algunas consideraciones e implicaciones en su implantación.: Revista Decisión Administrativa, 6. [Universidad Nacional de Colombia]. pp. 62-75.

- Llisterri, J. (2001). "Competitividad y desarrollo económico local". En: Documentos de trabajo BID.

- Llurdés, J. C. et al. (1999). Conflictos locacionales en territorios en crisis. Turismo y Residuos en Cardona (Barcelona). En: Anales de Geografía de la Universidad Complutense, 19. pp. 119-140.

- Mançano, B. (2008a). "Al perder mi tierra, estoy perdiendo mi país". En: Mirta, campesina paraguaya - Carumbey, San Pedro, Paraguay - 23 de octubre de 2008. Disponible en Internet: http://www.acciontierra.org/spip/IMG/pdf/BERNARDO_TIPOLOGIA_D E_TERRITORIOS_espanol.pdf (2008b). "La ocupación como una forma de acceso a la tierra en Brasil: una contribución teórica y metodológica". En: Recuperando la tierra. El resurgimiento de movimientos rurales en África, Asia y América Latina. Sam Moyo y Paris Yeros [coord.]. Buenos Aires: CLACS.

- Massiris, A. (2005). Fundamentos conceptuales y metodológicos del ordenamiento territorial. Tunja: UPTC.

- Mignolo, W. (2008). Capitalismo y geopolítica del conocimiento. El eurocentrismo y la filosofía de la liberación en el debate intelectual contemporáneo. Caracas: Editorial El Perro y la Rana.

- Ministerio de Comercio, Industria y Turismo. (2008). Política Nacional de Turismo, Plan Sectorial de Turismo 2008-2010: "Colombia, destino turístico de clase mundial". Bogotá: Ministerio de Comercio, Industria y Turismo.

- Mora, J. (2005). Plan Sectorial de Desarrollo Turístico de Honda-Tolima 2005-2007 "Unidos Para el Progreso del Turismo". Honda: Gobernación del Tolima-Municipio de Honda.

- Pabion, J. (2008). ?Les enjeux de l'écotourisme au Kirghizistan: une analyse anthropologique?. En : Journée Rochelaise de Recherche sur le Tourisme - 14 mars 2008 - Groupe Sup de Co La Rochelle.

- Polanyi, K. (1994). Nuestra obsoleta mentalidad de mercado. Cuadernos de economía, 19(20), pp. 194-266.

- Richman, K. (2008). ?Innocent Imitations? Authenticity and Mimesis in Haitian Vodou Art, Tourism, and Anthropology". Ethnohistory, 55(2). pp. 203-227.

- Santos, M. (2004). Por otra globalización. Del pensamiento único a la conciencia universal. Bogotá: Convenio Andrés Bello. 
- Torres, L. (2008). "Nueva ruralidad en territorios periféricos: los productores caprinos del noreste de Mendoza (Argentina)". En: Universitas Humanística, 66, pp: 199-218.

- Trouillot, M.R. (2001). "The Anthropology of the State: Close Encounters of a Deceptive Kind. Forum on Theory in Anthropology". Current Anthropology, 42(1), pp. 125-38.

- Sahlins, M. (2004). Cultura y razón práctica. Barcelona: Gedisa.

- Victoria, C. (2009). "Las políticas públicas y el desarrollo local el contexto regional del Eje Cafetero". En: Cuadernos de clase 01-02, Maestría Desarrollo regional y planificación del territorio. Manizales: Universidad Autónoma.

- Vidal, M. (2005). "Diagnóstico del potencial turístico de Honda". En: Magazín Cámara de Comercio de Honda, 3, pp. 3-35.

- World Turism Organisation - WTO. En Internet: http://unwto.org/facts/eng/pdf/highlights/UNWTO_Highlights07_sp_L R.pdf.

1. Universidad de Caldas. Departamento de Antropología y Sociales. Investigador del Grupo de Investigación Territorialidades. Correo electrónico: gregorio.hernandez@ucaldas.edu.co

2. En este artículo se abordan "los nuevos procesos de producción y ordenación del territorio rural y urbano", tópico que constituye un objetivo del proyecto "Dinámicas Territoriales en el Medio Magdalena (Caldas-Tolima): 1985-2008", financiado por la Red Alma Mater, la Universidad de Caldas y la Universidad del Tolima, y ejecutado por el Grupo de Investigación Territorialidades de la Universidad de Caldas y el Grupo de Estudios Urbanos y Regionales de la Universidad del Tolima. 3. Para acceder a las tendencias históricas del turismo, ver Goded (1998), y para acceder a estadísticas recientes, ver WTO (2007). 4. Dos de los problemas relacionados con el conocimiento de la actividad turística: 1) a pesar de la magnitud de su influjo en la economía mundial, no se ha logrado constituir un riguroso ámbito propio de estudio y es estudiada por economistas, sociólogos, antropólogos o profesionales de otra disciplina que la abordan con temor y con recelo, y 2) existe una marcada ausencia de estadísticas consolidadas global y localmente. 5. En este marco emergen diversas clasificaciones como el agroturismo, el ecoturismo, el turismo histórico, el turismo rural, entre otras. 6. "Estadísticas Básicas Municipales-Honda". El Tolima en cifras. Universidad de Ibagué. Disponible en línea: http://www.unibague.edu.co/portal/biblioteca/tolima/contenido_honda.html 7. "Plan de Desarrollo Construyendo en Paz la Dorada que todos queremos", vigencia 2008-2011. 8. Basta leer los títulos o apartados de algunos planes: Plan Sectorial de Desarrollo Turístico de Honda-Tolima 2005-2007 "Unidos Para el Progreso del Turismo"; Honda destino turístico y desarrollo competitivo, que es la primera área de desarrollo del Plan de Desarrollo Honda 2008-2011; o en Mariquita, Plan de Desarrollo Mariquita... siéntela lucha por ella. 9. En un lenguaje muy sofisticado y con una construcción argumentativa muy débil, podríamos citar a Llisterri (2001), asesor del BID. 10. Existen opciones con mayor fundamentación académica y mesuradas en el uso del lenguaje que propugnan por el desarrollo territorial, como la de Cuervo (2006).

11. Existen lineamientos de la UNESCO, a través de los cuales se concibe el territorio como: a) una herramienta de estructuración del destino turístico y de 
fortalecimiento de la competitividad, o b) un recurso de desarrollo económico, para dar respuestas a los impactos sobre la cultura y el medio-ambiente, creando las condiciones para la especialización productiva, tal y como se aprecia en el documento:

http://www.unesco.org.uy/mab/documentospdf/turismoresponsable/05_CM Naves_ppt.pdf

12. Veamos, por ejemplo: "El territorio y el medio local se convierten, de este modo, en lugar de estímulo de innovaciones y de amplificación de informaciones, actuando como un "actor" suministrador de recursos estratégicos y externalidades positivas para la eficiencia productiva y la competitividad empresarial. Entre los factores estratégicos para la construcción de estos entornos innovadores territoriales podemos diferenciar los de naturaleza tangible, tales como la disponibilidad de suelo industrial o parques empresariales, la naturaleza de los productos y procesos productivos, el medioambiente y las infraestructuras físicas, entre otros." (Alburquerque, 2001: 28). 13. Según lo expresa el Observatorio del Programa Presidencial de DDHH y DIH de la Vicepresidencia de la República. Diagnóstico departamental del Tolima. http://www.derechoshumanos.gov.co/observatorio_de_DDHH/departamento s/2007/tolima.pdf 